\title{
Fire-weather interaction fed the 2020 western USA gigafire
}

Xin Huang ${ }^{1,2}$, Jingyi Liu ${ }^{1}$, Ke Ding ${ }^{1,2}$, Zilin Wang ${ }^{1}$, Rong Tang ${ }^{1}$, Lian Xue ${ }^{1}$, Haikun Wang ${ }^{1,2}$, Qiang Zhang $^{3}$, Steven J. Davis ${ }^{3,4}$, Meinrat O. Andreae ${ }^{5,6,7}$, Aijun Ding ${ }^{1,2^{\star}}$

${ }^{1}$ School of Atmospheric Sciences, Nanjing University, Nanjing, 210023, China

${ }^{2}$ Frontiers Science Center for Critical Earth Material Cycling, Nanjing University, Nanjing, 210023, China

${ }^{3}$ Department of Earth System Science, Tsinghua University, Beijing 100084, China

${ }^{4}$ Department of Earth System Science, University of California, Irvine, CA 92697, USA

${ }^{5}$ Max Planck Institute for Chemistry, Mainz 55128, Germany

${ }^{6}$ Scripps Institution of Oceanography, University of California, San Diego, La Jolla, CA 92093, USA.

${ }^{7}$ Department of Geology and Geophysics, King Saud University, Riyadh, Saudi Arabia

*To whom correspondence may be addressed. Email: dingaj@nju.edu.cn

Author Contributions: A.D., X.H. designed research; X.H., J.L. performed research; X.H., A.D., R.T., Z.W., L.X., H.W. analyzed data; and X.H., A.D., S.J.D., M.O.A., Q.Z. wrote the paper.

Competing Interest Statement: The authors have no competing interests.

Classification: Physical Sciences.

Keywords: biomass burning | fire weather | western US | aerosol-radiation interaction | human health

\begin{abstract}
Wildfires threaten human lives, destroy infrastructure, disrupt economic activity, and damage ecosystem services. A record-breaking gigafire event ravaged the western United States (USA) in mid-September 2020, burning 1.2 million acres $\left(4,900 \mathrm{~km}^{2}\right)$ in Oregon and California, and resulting in severe smoke pollution with daily fine particulate matter $\left(\mathrm{PM}_{2.5}\right)$ concentrations over $300 \mu \mathrm{g} / \mathrm{m}^{3}$ for multiple days in many cities. Although previous studies have shown that regional warming escalates wildfire in the western USA, such an unprecedented fire cannot be explained by climate variability alone. Here we show that the synoptic-scale feedback between the wildfires and weather played an unexpectedly important role in accelerating the spread of this fire and also trapped pollutants in the shallow boundary layer over valley cities. Specifically, we find that aerosol-radiation interaction of the smoke plumes over the Cascade Mountains enhanced the
\end{abstract}


downslope winds and weakened the moisture transport, thereby forming a positive feedback loop that amplified the fires and contributed to $\sim 54 \%$ of estimated air-pollution related deaths. Our study underscores the complexity of the Earth system and the importance of understanding fundamental mechanisms to effectively mitigate disaster risks in a changing climate.

\section{Main Text}

\section{Introduction}

Wildfire has an enormous and increasing impact on lives and homes lost, human health, and ecosystem services (1-10). California, Oregon, Washington, and other states in the western United States (USA) are suffering from increasingly intense and destructive summertime wildfires, with records broken every few years (e.g., 2014, 2019, and 2020) (11-13). In turn, the severe haze pollution in downwind cities caused by such extreme wildfires has become the top air quality concern in the US $(10,14,15)$. For these reasons, western US wildfires and their impacts have been a major topic of research in recent decades, including considerable focus on the role of climate change(16-20).

It is therefore well known that meteorological parameters such as air temperature, humidity, wind, and precipitation, are key factors that modulate the intensity and persistence of wildfires $(17,21-$ 26). In addition, light-absorbing smoke aerosols emitted from burning biomass may substantially affect these meteorological parameters (27-30). However, little attention has been paid to the complex interactions among smoke aerosols, weather, and wildfire emissions-or to the effect of these interactions on the evolution and spread of extreme wildfires. Here, we use an atmospheric model and pollution measurements to demonstrate that such a fire-weather interaction indeed played a critical role in the spread and impacts of some of the extreme western US wildfires in 2020 , suggesting that this mechanism may be an important and overlooked driver of mounting wildfire impacts across the region.

\section{Results}

In September 2020, a series of wildfires in Oregon and California burned 1.2 million acres (defined as a "gigafire" for area $>1 \mathrm{M}$ acres), the largest area burned by fires in a single year in the state's recorded history (Fig. 1A) $(13,15,31)$. After the greatest daily fire emissions on 10 September, smoke from the fire spread over hundreds of millions of acres $\left(\sim 900,000 \mathrm{~km}^{2}\right.$ for Aerosol Optical Depth $>1$ ), stretching from the Pacific Ocean over most of Oregon and Washington, parts of California, Idaho, Nevada, and Canada (Fig. 2A and Fig. S1). The daily CO emissions were greater than those recorded from any previous fire in Oregon and California, and hazardous haze pollution (i.e. fine particulate matter $\mathrm{PM}_{2.5}>300 \mu \mathrm{g} / \mathrm{m}^{3}$, the "hazardous" category of the Air Quality Index) prevailed for several days in valley cities like Salem and the surrounding areas (Fig. 1B and Fig. S1) (13). During the fire, there were strong anomalies compared to the climatic mean in nearsurface water vapor $\left(Q_{2}\right)$ and east wind (zonal wind at $10-m$ altitude, $\left.U_{10}\right)$; Fig. $1 \mathrm{C}$ and $D$ ), and the large fire potential index (LFP; see Methods) (32) reached unprecedented levels (Fig. S2). Fig. 1C shows that local anomalies of these $Q_{2}, U_{10}$, and LFP parameters were particularly extreme during the fires in August and September of 2020. Recent studies have shown that the gigafire events were closely related to compound extremes/multiple drivers $(12,13)$, particularly the strong downslope easterly wind and fuel dryness. This is consistent with the record-setting LFP, which is derived from wind speed and dewpoint depression (32).

We explore the interaction mechanism between smoke aerosols, meteorology, and fire emissions, using numerical simulations with the meteorology-chemistry coupled model WRF-Chem for September 2020 (Methods). While aerosols modify meteorology via impacts on both radiation transfer and clouds, cloudless skies over the western US during the gigafire led the aerosolradiation interactions to dominate. Accordingly, we performed two parallel experiments, one with 
aerosol-radiation interactions (EXP_ARI) and another without (EXP_nARI), and validated the model with both in-situ and remote sensing measurements (Fig. S3-5). The results show that only the simulations that included aerosol-radiation interactions adequately reproduce the temperature profiles and the magnitude of $\mathrm{PM}_{2.5}$ concentrations (Fig. 2A and Fig. S4). During the 4-day period when coastal cities in Oregon and northern California suffered the most severe haze pollution (1013 September), aerosol optical depth (AOD) in these regions increased sharply to $>2$. Such a high aerosol loading substantially perturbed the radiation energy balance by trapping $>100 \mathrm{~W} / \mathrm{m}^{2}$ of incoming solar energy $(\sim 32 \%)$ in the atmosphere (Fig. S5), and in turn dramatically altered thermal stratification, as quantitatively revealed by the difference between our two parallel simulations.

Fig. 2B shows that these aerosol-radiation interactions tended to warm the smoke layer and cool the land surface over the affected areas of western US, thereby suppressing the development of the planetary boundary layer (PBL). Under the most extreme conditions on the afternoon (16:00 LT) of 12 September, the decrease in near-surface temperature was $6{ }^{\circ} \mathrm{C}$ in Salem, accompanied by a decrease in the PBL height of almost $500 \mathrm{~m}$. These modifications in the thermal stratification in the lower troposphere are consistent with those observed in regions with high loading of black carbon (BC) from biomass burning and fossil fuel sources $(9,27)$. Meanwhile, our results show that these radiative effects increased near-surface $\mathrm{PM}_{2.5}$ concentrations by over $100 \mu \mathrm{g} / \mathrm{m}^{3}$ on the western slope of Oregon's Cascade Mountains, while at altitudes of 1-2 km PM2.5 concentrations decreased by as much as $50 \mu \mathrm{g} / \mathrm{m}^{3}$ (dashed contours in Fig. 2B). Such opposite $\mathrm{PM}_{2.5}$ changes between the lower and upper layers have been attributed to the aerosol-PBL interaction caused by light-absorbing aerosols (e.g., BC) from wildfires(33, 34). Specifically, smoke aerosols stabilized the PBL by warming the upper air and cooling the surface, thereby greatly weakening turbulent mixing and trapping the pollution in a much shallower PBL (33).

In addition to modifying temperature, aerosol-radiation interactions substantially perturbed both vertical and horizontal winds (arrows in Fig. $2 \mathrm{~B}$ and $\mathrm{C}$ ). Specifically, surface cooling led to a strong easterly wind anomaly in the near-surface wind (the 4-day average was about 3-4 m/s in the lower $\mathrm{PBL}$ ), especially down the western slope of the Cascade Mountains, despite an overall onshore wind anomaly over the ocean and above the PBL. The wind response in the coastal areas was linked to the aerosol-radiation interactions, which induced a large-scale circulation change associated with the overall enhancement of low pressure off the western coastline (Extended Data Fig. S5-6). Further, in addition to the strong downslope east wind anomaly within the PBL, the aerosol-PBL interaction over the land area with high AOD prevented the onshore transport of water vapor from the Pacific Ocean (Fig. 2B). Thus, our results indicate that near-surface water vapor $\left(Q_{2}\right)$ was dramatically reduced by aerosol-radiation interactions in most of the wildfire area during mid-September 2020, with the largest decreases in the Cascade Mountains of Oregon. This is the area where wildfires were concentrated (Fig. 1D), and aerosol feedbacks can partly explain the 2020 anomaly compared to the climatology (Fig. S7). Associated with the enhanced downslope wind, the windspeed was greatly amplified (Fig. 2E). The differences of both $\mathrm{Q}_{2}$ and 10-meter wind speed (WS 10 ) between EXP_ARI and EXP_nARI show good correlation with AOD (Fig. 3A and Fig. S8, $A$ and B) (27). Fig. $3 A$ shows the systematic changes in both $Q_{2}$ and $W S_{10}$ (by $\sim 40 \%$ ) at very high $A O D$ (e.g., $A O D=3$; see also Fig. S8B).

Our simulations thus demonstrate that aerosol-radiation interactions of wildfire smoke enhanced both dryness and wind speed during the 2020 gigafire. The stronger easterly wind over the western slope of the Cascade Mountains can be explained as reinforced mountain breezes due to the substantial reduction in solar radiation under high AOD (Fig. 2 B and C, and Fig. S5-6). Since the smoke plumes during 10-13 September spread over an area of thousands of square $\mathrm{km}$ and the aerosol-induced changes in circulation occurred over a similar spatial extent, we carried out additional simulations to quantify the role of aerosol-radiation interactions over ocean and land, respectively, on the change of meteorological parameters (Methods). As shown in Fig. S8, C and $\mathrm{D}$, aerosol-radiation interactions were the main contributor to modifying $\mathrm{Q}_{2}$ and $W \mathrm{~S}_{10}$ over the Cascade Mountains, indicating the importance of the smoke plumes on the evolution of local thermal circulations such as the mountain-valley breezes over mountainous areas. Given the fact 
that a very strong gradient of water vapor existed across the western US during the fires (Fig. S6C), the humidity in the fire region would definitely be extremely sensitive to changes in the wind field, particularly zonal winds. The enhanced easterly winds can also influence humidity and air temperature through the foehn wind process, which has been extensively acknowledged as a critical factor triggering wildfire in the western USA $(23,32,35)$.

Decreased water vapor concentrations, combined with increased wind speed, resulted in a substantial increase of the large fire potential(32) in Oregon and the western USA (Fig. 3B). In the Cascade Mountains where fires were most intense, aerosol-radiation interactions increased the LFP index by $>100 \%$. Emissions and near-surface concentrations of $\mathrm{PM}_{2.5}$ induced by aerosolradiation interactions also exacerbated mortality in valley cities of the western US (Fig. S9). We estimate that aerosol-PBL interactions alone increased fire-related air pollution deaths by $\sim 16 \%$. However, considering that wildfire emissions were enhanced by smoke-driven changes in meteorology, the full effect of fire-weather interactions are better reflected by the increase in large fire potential (LFP; Fig. 3B). Scaling fire emissions by LFP, we find that fire-weather interactions accounted for a $54 \%$ increase in air pollution deaths in the western US, about $3 / 4$ of which $(+41 \%$ deaths) were directly due to emission enhancement and1/4 (+13-16\% deaths) were due to aerosolPBL interactions. Estimated deaths more than doubled due to these fire-weather interactions in cities of Oregon and Washington, particularly those located in valleys nearby or downwind of the Cascade Mountains.

Our results provide a comprehensive demonstration of an unexpectedly strong feedback between wildfire and weather in the western US. Specifically, increased AOD from wildfire suppresses the development of the PBL and enhances orographic winds, thereby increasing the large fire potential on the western slope of the Cascade Mountains via higher wind speed and lower humidity. Moreover, the aerosol-PBL interaction exacerbates $\mathrm{PM}_{2.5}$ concentrations in the valley cities by suppressing convection and weakening diffusion, and the strengthened wildfire emission further enhances the haze pollution and AOD to reinforce the feedback loop (Fig. 4). This fire-weather coupling is distinct from pyroconvection (36), which has not been detected from satellite imagery during these gigafire events, probably due to extremely stable atmospheric conditions. Considering the much larger scale of aerosol-radiation induced wind enhancement and fire spread compared to the area affected by pyroconvection, the mechanism we identify here can amplify all sizes of fires and impact many western US fires.

\section{Discussion}

Our findings emphasize the complexity of fire-weather interactions in the Earth system, and the critical importance of improving our understanding of such mechanisms to prioritize fire prevention and suppression efforts and thus mitigate the impacts of extreme wildfires $(7,31)$. For example, our results indicate there may be an unexpected nonlinear benefit from early fire suppression efforts. Considering that the feedback loop shown in Fig. 4 acts over a temporal scale of 1-2 days, we modeled a $50 \%$ reduction in fire emissions on 8-9 September that would have resulted from an effective early fire suppression (See Methods), and find that even with fire-weather interactions, air pollution deaths would have been reduced by as much as $78 \%$ - saving about two dozen lives on 11 September alone. Indeed, given the persistence and spread of wildfires and fire-weather feedback, early-stage fire suppression efforts (e.g., the first two days) may be able to succeeded in avoiding such gigafires. Moreover, strategic and early fire management, e.g. more effort on fire suppression of the forests upslope of populated areas, could greatly reduce the impacts of wildfirerelated air pollution to save lives(37). Further research and support from state-of-the-art forecast models with related feedback processes will be necessary to accurately target such early management resources. But given increasing trends of wildfire impacts in many regions (and especially those with Mediterranean climates with strong water vapor gradients and complex topography), the feedback loop we identify may ultimately prove critical in understanding and reducing fire risks. 


\section{Materials and Methods}

Observations on wildfire, air quality, and meteorology. The Moderate Resolution Imaging Spectroradiometer (MODIS) onboard the Terra and Aqua satellites has been monitoring fires since the year 2001, and the Thermal Anomalies and Fire product MOD14A1 and MYD14A1 were collected for demonstrating the spatiotemporal variation of wildfires in the western US. The MODIS Aerosol Product MOD04, which provides daily aerosol optical depth, was adopted to validate model performance on reproducing spatial patterns of fire smoke aerosol. In addition, the in-situ measurements of $\mathrm{PM}_{2.5}$ concentrations, which are routinely recorded by the Air Quality System of United States Environmental Protection Agency (USEPA), were also utilized for the purpose of illustrating the temporal variation of air pollution and for evaluating the model simulation. To investigate the relationship between wildfire intensity and weather conditions, we also used a large number of ground-based and radiosonde meteorological observations, which are archived at the National Climatic Data Center of the National Oceanic and Atmospheric Administration.

Regional meteorology and chemical coupled modeling. WRF-Chem, the chemistry version of the Weather Research and Forecasting model (version 3.7.1), which simulates trace gases and particulates interactively with the meteorological fields, was applied to quantitatively understand the feedback between fire smoke and meteorology. The model domain covered the US with a grid resolution of $18 \mathrm{~km}$ and 35 vertical layers. The NCEP global final analysis (FNL) data was used to provide meteorological initial and boundary conditions. The Yonsei University (YSU) scheme was applied to parameterize boundary layer processes. Key physical parameterizations included the Noah land surface scheme for representing land-atmosphere interactions, and the RRTMG radiation scheme. For the numerical representation of air pollution, the carbon-bond photochemical mechanism combined with the MOSAIC (Model for Simulating Aerosol Interactions and Chemistry) aerosol module were utilized. The optical properties of aerosols were computed as a function of wavelength and three-dimensional positions. The interactions between aerosols and clouds have been described in more detail in Grell et al. (2011)(38).

Both biomass burning and anthropogenic emissions were included. Anthropogenic emissions were derived from the Emissions Database for Global Atmospheric Research (EDGAR)(39). The fire inventory from NCAR (FINN), which uses satellite observations of active fires and land cover, together with emission factors and fuel loadings to provide daily, highly-resolved biomass burning emissions(40), was employed to characterize the fire emissions in the model. It has been demonstrated that the FINN inventory tends to underestimate by almost half the intensity of large fires in the western US(41). Thus, we conducted sensitivity tests by doubling the emission intensity and compared them with in-situ observations (Fig. S3). Clearly, the doubled emissions resulted in better model performance on the magnitude and temporal variation of $\mathrm{PM}_{2.5}$ concentrations, and were used for the further analysis. Biomass burning injection height was derived from satellite detections(42). To provide more realistic chemical initial conditions, a 10day spin-up period was applied and the simulations covered from 28 August to 16 September 2020. To determine the role of biomass burning aerosol on meteorology, multiple parallel simulations were performed, i.e., one scenario including (EXP_ARI) and another excluding aerosol-radiation interaction (EXP_nARI).

Large fire potential and health impact assessment. The near-surface weather characteristics that are closely related to wildfire, are represented by the large fire potential (LFP) index, which has been proven to well predict fire intensity in the western US in previous studies(32) and in Fig. S2. It is calculated as follows(32)

$L F P=0.001 W_{s}^{2} D_{d}$

where $W_{s}$ is the 10-m wind velocity and $D_{d}$ is the 2-m dewpoint depression. As shown in Fig. S9, the fire emission in the western US is linearly correlated with LFP in the 2020 fire season. On the 
basis of this relationship, we approximate the fire emission changes due to aerosol-induced perturbations in meteorology and conduct simulations considering this fire emission enhancement.

Wildfire events can lead to a rapid growth of $\mathrm{PM}_{2.5}$ concentrations to pathogenic level and jeopardize human health. Based on existing epidemiological studies (10), the daily mortality attributed to elevated ambient $\mathrm{PM}_{2.5}$ in different scenarios was estimated as the potential health impacts associated with wildfire events in this work.

We calculated the total mortality burden $(\mathrm{M})$ in each gird cell according to an exposure response function(43-45):

$M=A F \times B d \times P$

$\mathrm{AF}=\frac{\mathrm{RR}(\mathrm{C})-1}{\mathrm{RR}(\mathrm{C})}$

where $A F$ is the attributable fraction of biomass burning-induced $\mathrm{PM}_{2.5}$ pollution; $\mathrm{B}_{\mathrm{d}}$ is the daily baseline risk of deaths from non-communicable diseases in US, adopted from the Global Burden of Diseases Study 2019 (available at http://ghdx.healthdata.org/gbd-results-tool); P is the total population of each grid cell and $R R(C)$ is the relative risk of each gird cell at a given $\mathrm{PM}_{2.5}$ concentration $\mathrm{C}$ (in $\mu \mathrm{g} / \mathrm{m}^{3}$ ) expressed as:

$\operatorname{RR}(C)=\exp \left(\gamma \times\left(C-C_{0}\right)\right)$

where $\mathrm{C}_{0}$ is the counterfactual $\mathrm{PM}_{2.5}$ concentration without additional contribution to mortality risk; $Y$ is the empirical excess mortality per unit increase in $\mathrm{PM}_{2.5}$, which is adopted as 0.00104 at the $95 \%$ confidence intervals(44).

$\Delta \mathrm{M}_{\mathrm{i}, \mathrm{j}}=\mathrm{M}_{\mathrm{i}, \mathrm{j}}(\mathrm{S} 2)-\mathrm{M}_{\mathrm{i}, \mathrm{j}}(\mathrm{S} 1)$

The temporal and spatial distributions of mortality under different simulation scenarios were obtained based on Eq. 2-4, and then summed up for the western US. The differences of mortality attributed to $\mathrm{PM}_{2.5}$ in each grid cell $\left(\Delta \mathrm{M}_{\mathrm{i}, \mathrm{j}}\right)$ between different scenarios $\left(\mathrm{S}_{n}\right)$ were calculated by $\mathrm{Eq}$. 5 to respectively represent the health impacts of fire emission change and smoke aerosolradiation interaction.

\section{Data Availability}

MODIS thermal anomalies and aerosol products are available at https://ladsweb.modaps.eosdis.nasa.gov/archive/allData/6/MOD14A1/ and https://ladsweb.modaps.eosdis.nasa.gov/archive/allData/61/MOD04_L2/. FINN fire emissions data is openly accessible at https://www.acom.ucar.edu/Data/fire/. The grid-ded anthropogenic emission data EDGAR is obtained from https://edgar.jrc.ec.europa.eu/dataset_ap50. Ambient air quality monitoring data can be obtained at https://aqs.epa.gov/aqsweb/airdata/download_files.html. The radiosonde and surface meteorological observations are archived at National Center for Environmental Information (NCEI) (ftp://ftp.ncdc.noaa.gov/pub/data/noaa/ and ftp://ftp.ncdc.noaa.gov/pub/data/igra). The gridded population density data is available at https://sedac.ciesin.columbia.edu/data/collection/gpw-v4. Data processing techniques are available on request from the corresponding author. The source code of the WRF-Chem model is archived in the UCAR data repository (http://www2.mmm.ucar.edu/wrf/users/download).

\section{Acknowledgments}


This paper is a non-peer reviewed preprint submitted to EarthArXiv

This work was supported by the National Natural Science Foundation of China (41725020, 41922038), the Fundamental Research Funds for the Central Universities (DLTD2107), and the Jiangsu Collaborative Innovation Center for Climate Change. We are grateful to the HighPerformance Computing \& Massive Data Center (HPC\&MDC) of School of Atmospheric Science, Nanjing University for doing the numerical calculations in this paper on its Blade cluster system.

\section{References}

1. A. L. Westerling, H. G. Hidalgo, D. R. Cayan, T. W. Swetnam, Warming and earlier spring increase Western U.S. forest wildfire activity. Science. 313, 940-943 (2006).

2. D. Wang, D. Guan, S. Zhu, M. Mac Kinnon, G. Geng, Q. Zhang, H. Zheng, T. Lei, S. Shao, P. Gong, S. J. Davis, Economic footprint of California wildfires in 2018. Nat. Sustain. 4, 252-260 (2021).

3. C. E. Reid, M. Brauer, F. H. Johnston, M. Jerrett, J. R. Balmes, C. T. Elliott, Critical review of health impacts of wildfire smoke exposure. Environ. Health Perspect. 124, 1334-1343 (2016).

4. D. A. Jaffe, S. M. O’Neill, N. K. Larkin, A. L. Holder, D. L. Peterson, J. E. Halofsky, A. G. Rappold, Wildfire and prescribed burning impacts on air quality in the United States. J. Air Waste Manag. Assoc. 70, 583-615 (2020).

5. P. J. Grutzen, M. O. Andreae, Biomass burning in the tropics: Impact on atmospheric chemistry and biogeochemical cycles. Science. 250, 1669-1678 (1990).

6. M. Burke, A. Driscoll, S. Heft-Neal, J. Xue, J. Burney, M. Wara, The changing risk and burden of wildfire in the United States. Proc. Natl. Acad. Sci. U. S. A. 118 (2021).

7. D. M. J. S. Bowman, J. K. Balch, P. Artaxo, W. J. Bond, J. M. Carlson, M. A. Cochrane, C. M. D’Antonio, R. S. DeFries, J. C. Doyle, S. P. Harrison, F. H. Johnston, J. E. Keeley, M. A. Krawchuk, C. A. Kull, J. B. Marston, M. A. Moritz, I. C. Prentice, C. I. Roos, A. C. Scott, T. W. Swetnam, G. R. Van Der Werf, S. J. Pyne, Fire in the earth system. Science. 324, 481-484 (2009).

8. M. O. Andreae, P. Merlet, Emission of trace gases and aerosols from biomass burning. Global Biogeochem. Cycles. 15, 955-966 (2001).

9. N. Andela, D. C. Morton, L. Giglio, Y. Chen, G. R. Van Der Werf, P. S. Kasibhatla, R. S. DeFries, G. J. Collatz, S. Hantson, S. Kloster, D. Bachelet, M. Forrest, G. Lasslop, F. Li, S. Mangeon, J. R. Melton, C. Yue, J. T. Randerson, A human-driven decline in global burned area. Science. 356, 1356-1362 (2017).

10. R. Aguilera, T. Corringham, A. Gershunov, T. Benmarhnia, Wildfire smoke impacts respiratory health more than fine particles from other sources: observational evidence from Southern California. Nat. Commun. 12 (2021).

11. R. Barbero, J. T. Abatzoglou, E. A. Steel, N. K. Larkin, Modeling very large-fire occurrences over the continental United States from weather and climate forcing. Environ. Res. Lett. 9, 124009 (2014).

12. M. S. Khorshidi, P. E. Dennison, M. R. Nikoo, A. Aghakouchak, C. H. Luce, M. Sadegh, Increasing concurrence of wildfire drivers tripled megafire critical danger days in Southern California between 1982 and 2018. Environ. Res. Lett. 15, 104002 (2020).

13. J. T. Abatzoglou, D. E. Rupp, L. W. O'Neill, M. Sadegh, Compound Extremes Drive the Western Oregon Wildfires of September 2020. Geophys. Res. Lett. 48 (2021).

14. C. D. McClure, D. A. Jaffe, US particulate matter air quality improves except in wildfireprone areas. Proc. Natl. Acad. Sci. U. S. A. 115, 7901-7906 (2018).

15. P. E. Higuera, J. T. Abatzoglou, Record-setting climate enabled the extraordinary 2020 fire season in the western United States. Glob. Chang. Biol. 27, 1-2 (2021).

16. J. T. Abatzoglou, A. P. Williams, Impact of anthropogenic climate change on wildfire across western US forests. Proc. Natl. Acad. Sci. U. S. A. 113, 11770-11775 (2016).

17. M. Goss, D. L. Swain, J. T. Abatzoglou, A. Sarhadi, C. A. Kolden, A. P. Williams, N. S. Diffenbaugh, Climate change is increasing the likelihood of extreme autumn wildfire conditions across California. Environ. Res. Lett. 15, 094016 (2020). 
18. W. M. Jolly, M. A. Cochrane, P. H. Freeborn, Z. A. Holden, T. J. Brown, G. J. Williamson, D. M. J. S. Bowman, Climate-induced variations in global wildfire danger from 1979 to 2013. Nat. Commun. 6, 1-11 (2015).

19. A. P. Williams, J. T. Abatzoglou, A. Gershunov, J. Guzman-Morales, D. A. Bishop, J. K. Balch, D. P. Lettenmaier, Observed Impacts of Anthropogenic Climate Change on Wildfire in California. Earth's Futur. 7, 892-910 (2019).

20. D. Touma, S. Stevenson, F. Lehner, S. Coats, Human-driven greenhouse gas and aerosol emissions cause distinct regional impacts on extreme fire weather. Nat. Commun. 12, 1-8 (2021).

21. J. S. Littell, D. L. Peterson, K. L. Riley, Y. Liu, C. H. Luce, A review of the relationships between drought and forest fire in the United States. Glob. Chang. Biol. 22, 2353-2369 (2016).

22. J. L. Crockett, A. Leroy Westerling, Greater temperature and precipitation extremes intensify Western U.S. droughts, wildfire severity, and sierra Nevada tree mortality. J. Clim. 31, 341-354 (2018).

23. M. G. Pereira, J. Parente, M. Amraoui, A. Oliveira, P. M. Fernandes, The role of weather and climate conditions on extreme wildfires. Extrem. Wildfire Events Disasters Root Causes New Manag. Strateg., 55-72 (2019).

24. N. S. Diffenbaugh, D. L. Swain, D. Touma, Anthropogenic warming has increased drought risk in California. Proc. Natl. Acad. Sci. U. S. A. 112, 3931-6 (2015).

25. Z. A. Holden, A. Swanson, C. H. Luce, W. M. Jolly, M. Maneta, J. W. Oyler, D. A. Warren, R. Parsons, D. Affleck, Decreasing fire season precipitation increased recent western US forest wildfire activity. Proc. Natl. Acad. Sci. 115, E8349-E8357 (2018).

26. J. E. Halofsky, D. L. Peterson, B. J. Harvey, Changing wildfire, changing forests: the effects of climate change on fire regimes and vegetation in the Pacific Northwest, USA. Fire Ecol. 16 (2020).

27. T. C. Bond, S. J. Doherty, D. W. Fahey, P. M. Forster, T. Berntsen, B. J. Deangelo, M. G. Flanner, S. Ghan, B. Kärcher, D. Koch, S. Kinne, Y. Kondo, P. K. Quinn, M. C. Sarofim, M. G. Schultz, M. Schulz, C. Venkataraman, H. Zhang, S. Zhang, N. Bellouin, S. K. Guttikunda, P. K. Hopke, M. Z. Jacobson, J. W. Kaiser, Z. Klimont, U. Lohmann, J. P. Schwarz, D. Shindell, T. Storelvmo, S. G. Warren, C. S. Zender, Bounding the role of black carbon in the climate system: A scientific assessment. J. Geophys. Res. Atmos. 118, 5380-5552 (2013).

28. P. E. Saide, S. N. Spak, R. B. Pierce, J. A. Otkin, T. K. Schaack, A. K. Heidinger, A. M. Da Silva, M. Kacenelenbogen, J. Redemann, G. R. Carmichael, Central American biomass burning smoke can increase tornado severity in the U.S. Geophys. Res. Lett. 42, 956-965 (2015).

29. P. Zuidema, J. Redemann, J. Haywood, R. Wood, S. Piketh, M. Hipondoka, P. Formenti, Smoke and clouds above the southeast Atlantic: Upcoming field campaigns probe absorbing aerosol's impact on climate. Bull. Am. Meteorol. Soc. 97, 1131-1135 (2016).

30. X. Huang, A. Ding, Aerosol as a critical factor causing forecast biases of air temperature in global numerical weather prediction models. Sci. Bull. (2021).

31. A. B. Leverkus, S. Thorn, D. B. Lindenmayer, J. G. Pausas, Wildfire debate needs science, not politics. Science. 370, 416-417 (2020).

32. T. Rolinski, S. B. Capps, W. Zhuang, Santa Ana winds: A descriptive climatology. Weather Forecast. 34, 257-275 (2019).

33. Z. Li, J. Guo, A. Ding, H. Liao, J. Liu, Y. Sun, T. Wang, H. Xue, H. Zhang, B. Zhu, Aerosol and boundary-layer interactions and impact on air quality. Natl. Sci. Rev. 4, 810-833 (2017).

34. A. K. Kochanski, D. V. Mallia, M. G. Fearon, J. Mandel, A. H. Souri, T. Brown, Modeling Wildfire Smoke Feedback Mechanisms Using a Coupled Fire-Atmosphere Model With a Radiatively Active Aerosol Scheme. J. Geophys. Res. Atmos. 124, 9099-9116 (2019).

35. D. V. Mallia, A. K. Kochanski, K. E. Kelly, R. Whitaker, W. Xing, L. E. Mitchell, A. Jacques, A. Farguell, J. Mandel, P. E. Gaillardon, T. Becnel, S. K. Krueger, J. Geophys. Res. Atmos., in press. 
36. D. A. Peterson, E. J. Hyer, J. R. Campbell, M. D. Fromm, J. W. Hair, C. F. Butler, M. A. Fenn, The 2013 Rim Fire: Implications for Predicting Extreme Fire Spread, Pyroconvection, and Smoke Emissions. Bull. Am. Meteorol. Soc. 96, 229-247 (2015).

37. M. A. Moritz, E. Batllori, R. A. Bradstock, A. M. Gill, J. Handmer, P. F. Hessburg, J. Leonard, S. McCaffrey, D. C. Odion, T. Schoennagel, A. D. Syphard, Learning to coexist with wildfire. Nature. 515, 58-66 (2014).

38. G. Grell, S. R. Freitas, M. Stuefer, J. Fast, Inclusion of biomass burning in WRF-Chem: Impact of wildfires on weather forecasts. Atmos. Chem. Phys. 11, 5289-5303 (2011).

39. M. Crippa, E. Solazzo, G. Huang, D. Guizzardi, E. Koffi, M. Muntean, C. Schieberle, R. Friedrich, G. Janssens-Maenhout, High resolution temporal profiles in the Emissions Database for Global Atmospheric Research. Sci. Data. 7, 1-17 (2020).

40. C. Wiedinmyer, S. K. Akagi, R. J. Yokelson, L. K. Emmons, J. A. Al-Saadi, J. J. Orlando, A. J. Soja, The Fire INventory from NCAR (FINN): A high resolution global model to estimate the emissions from open burning. Geosci. Model Dev. 4, 625-641 (2011).

41. S. N. Koplitz, C. G. Nolte, G. A. Pouliot, J. M. Vukovich, J. Beidler, Influence of uncertainties in burned area estimates on modeled wildland fire PM2.5 and ozone pollution in the contiguous U.S. Atmos. Environ. 191, 328-339 (2018).

42. M. V. Martin, R. A. Kahn, M. G. Tosca, A global analysis of wildfire smoke injection heights derived from space-based multi-angle imaging. Remote Sens. 10, 1609 (2018).

43. J. S. Apte, J. D. Marshall, A. J. Cohen, M. Brauer, Addressing Global Mortality from Ambient PM2.5. Environ. Sci. Technol. 49, 8057-8066 (2015).

44. R. W. Atkinson, S. Kang, H. R. Anderson, I. C. Mills, H. A. Walton, Epidemiological time series studies of PM2.5 and daily mortality and hospital admissions: A systematic review and meta-analysis. Thorax. 69 (2014), pp. 660-665.

45. P. Giani, S. Castruccio, A. Anav, D. Howard, W. Hu, P. Crippa, Short-term and long-term health impacts of air pollution reductions from COVID-19 lockdowns in China and Europe: a modelling study. Lancet Planet. Heal. 4, e474-e482 (2020). 
Figures
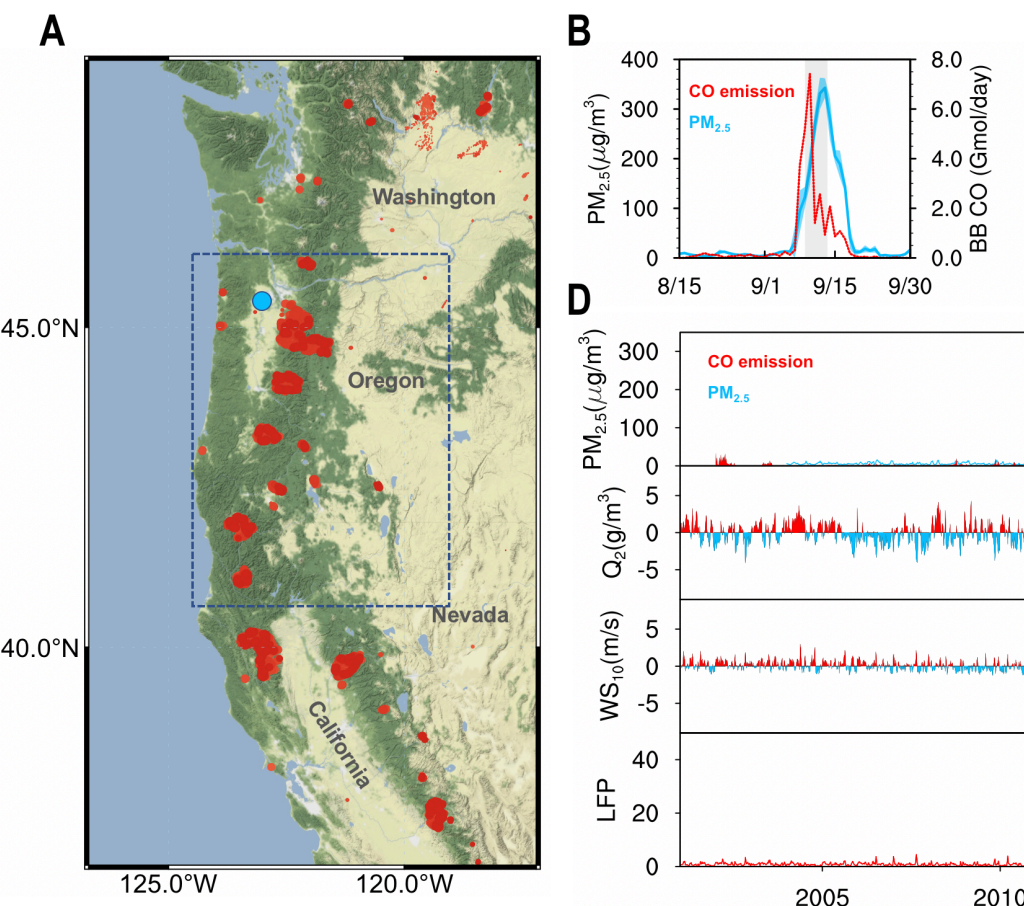

C
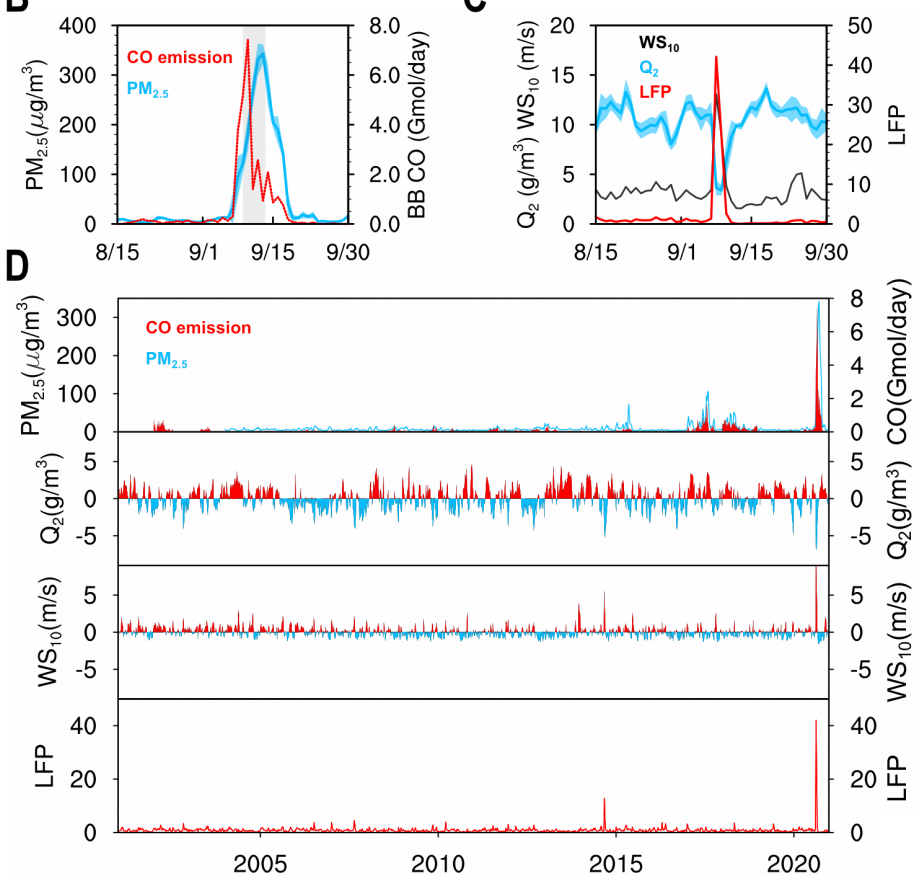

Figure 1. Recording-breaking western US wildfire events and weather anomalies in 2020. (A) Vegetation map and fire spots over the western US in September 2020. Salem station in Oregon is marked in blue dot. (B-C) Daily variations of biomass burning $\mathrm{CO}$ emission, $\mathrm{PM}_{2.5}$ observations in Oregon Cascade Mountains (blue rectangle in A), 2-m water vapor $\left(Q_{2}\right)$ and 10-meter wind speed $\left(\mathrm{WS}_{10}\right)$ and large fire potential (LFP) at Salem station in August-September 2020. The blue and red shadings show the $25-75^{\text {th }}$ percentile of $P_{2.5}$ and $Q_{2}$, respectively. The grey area in $B$ marks the most polluted periods with the largest fire emission in Oregon. (D) Time series of CO emission, PM $2.5, Q_{2}, W_{10}$ and LFP in August-September from 2001 to 2020. 

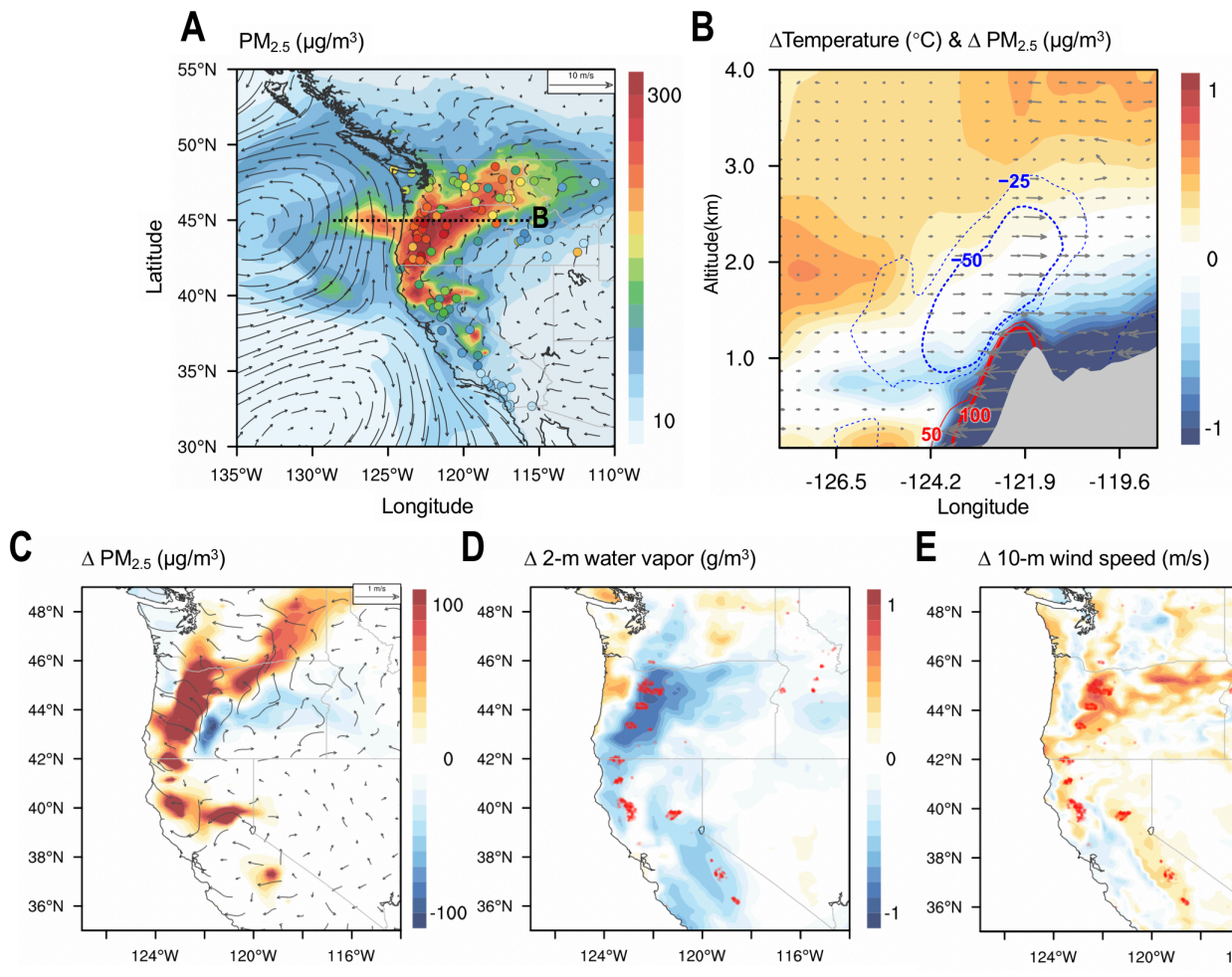

D $\Delta$ 2-m water vapor $\left(\mathrm{g} / \mathrm{m}^{3}\right)$
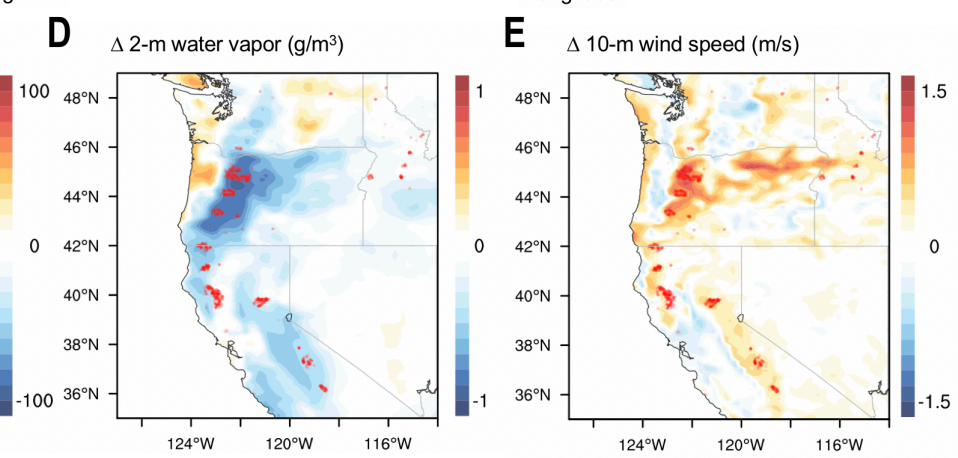

Figure 2. Model simulation of aerosol-PBL interaction during the 2020 western US Gigafire. (A) Simulated (contour) and observed (dots) near-surface $\mathrm{PM}_{2.5}$ concentrations in the western US during 10-13 September, when Oregon featured the highest fire emission and $\mathrm{PM}_{2.5}$ level, as shown by the grey shading in Fig. 1B. (B) Cross section of ARI-induced perturbations in air temperature (color), wind (arrows), and $\mathrm{PM}_{2.5}$ (contours) along the dashed line in A. (C) Spatial distributions of near-surface $\mathrm{PM}_{2.5}$ and circulation changes due to ARI caused by the smoke. (DE) Spatial distributions of $Q_{2}$ and $W S_{10}$ changes due to ARI overlaid by fire spots during the 2020 western US gigafire. 
A

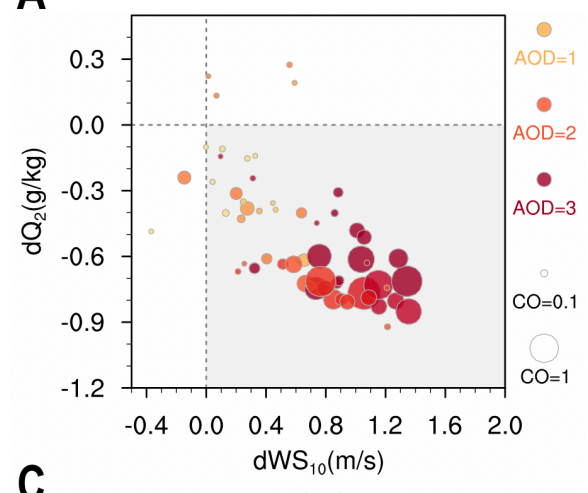

C

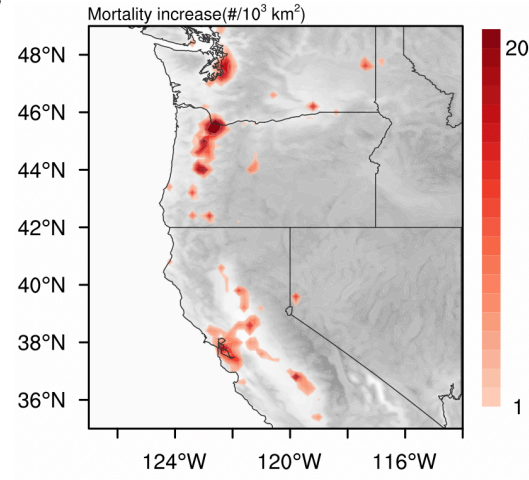

B

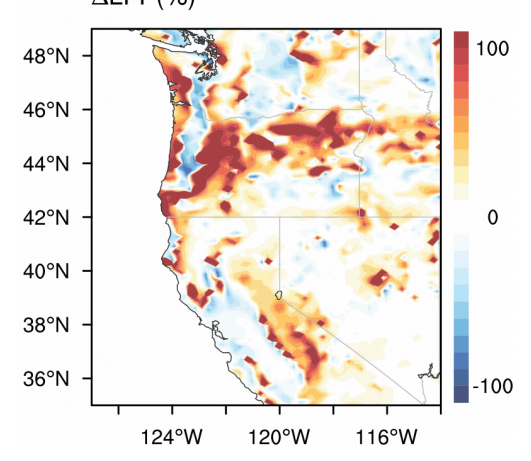

D

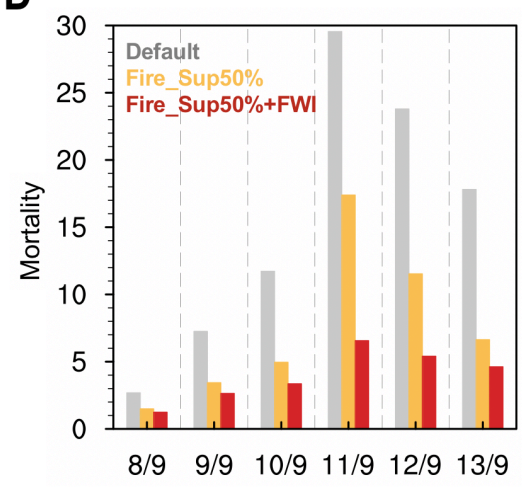

Figure 3. Impact of fire-weather interaction on meteorology and excess mortality. (A) Scatter plot of $Q_{2}$ and $W S_{10}$ changes due to ARI under different AOD levels and biomass burning $C O$ emission intensity (Mmol $/ \mathrm{km}^{2} /$ day). (B)Spatial distributions of LFP increment due to ARI during 10-13 September in the western US. (C) Spatial distributions of excess mortality due to fireweather interaction in the western US. (D) Potentially preventable mortality via early fire suppression. Grey, orange, and red bars show daily mortality in the western US while taking no fire management (Default), suppressing 50\% fire (Fire_Sup50\%) and with additional fire-weather interaction considered (Fire_Sup50\%+FWI). 


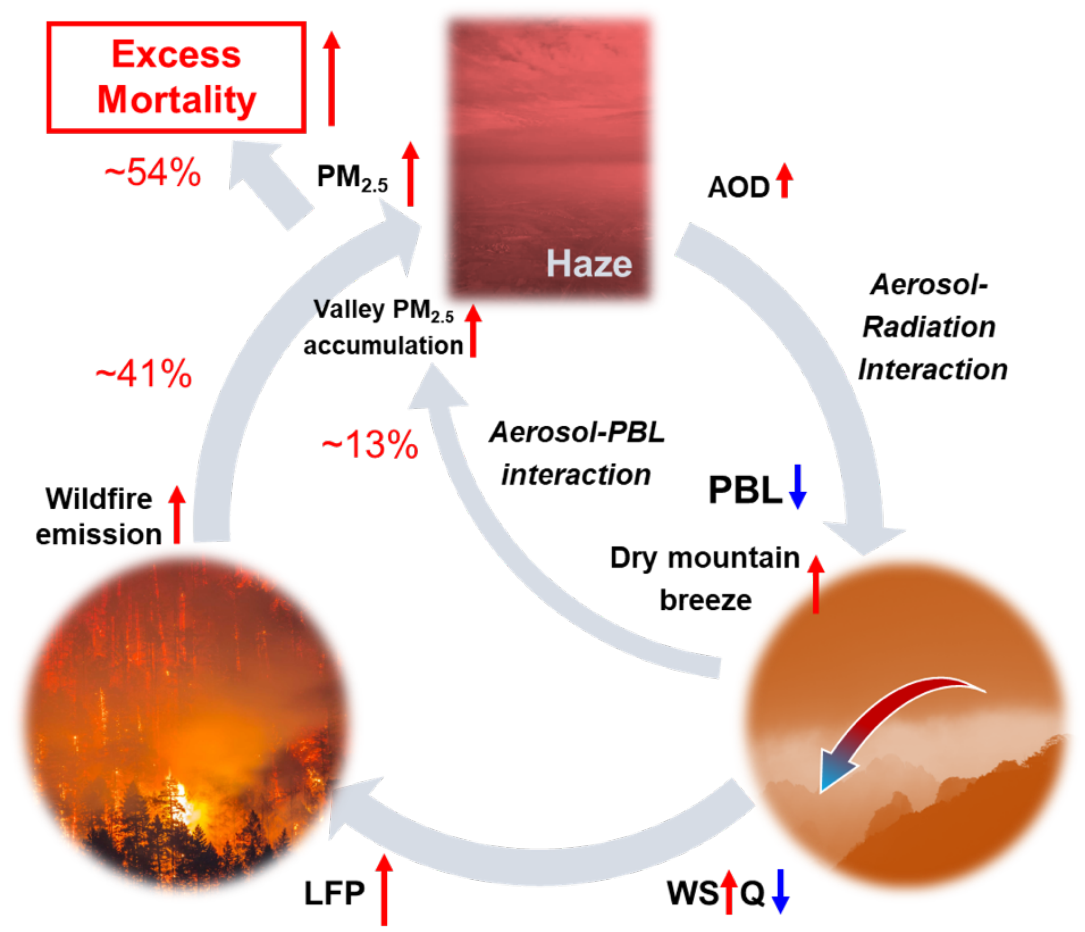

Figure 4. Conceptual model of the fire-weather interaction in the western US. Gray arrows indicate the linkage between wildfire, air quality, and thermal circulations. Red and blue arrows show the increase and decrease, respectively, of each parameter with the width illustrating the magnitude. 


\section{Supplementary Information for}

\section{Fire-weather interaction fed the 2020 western USA gigafire}

Xin Huang, Jingyi Liu, Ke Ding, Zilin Wang, Rong Tang, Lian Xue, Haikun Wang, Qiang Zhang, Steven Davis, Meinrat Andreae, Aijun Ding

This PDF file includes:

Figures $\mathrm{S} 1$ to $\mathrm{S9}$ 

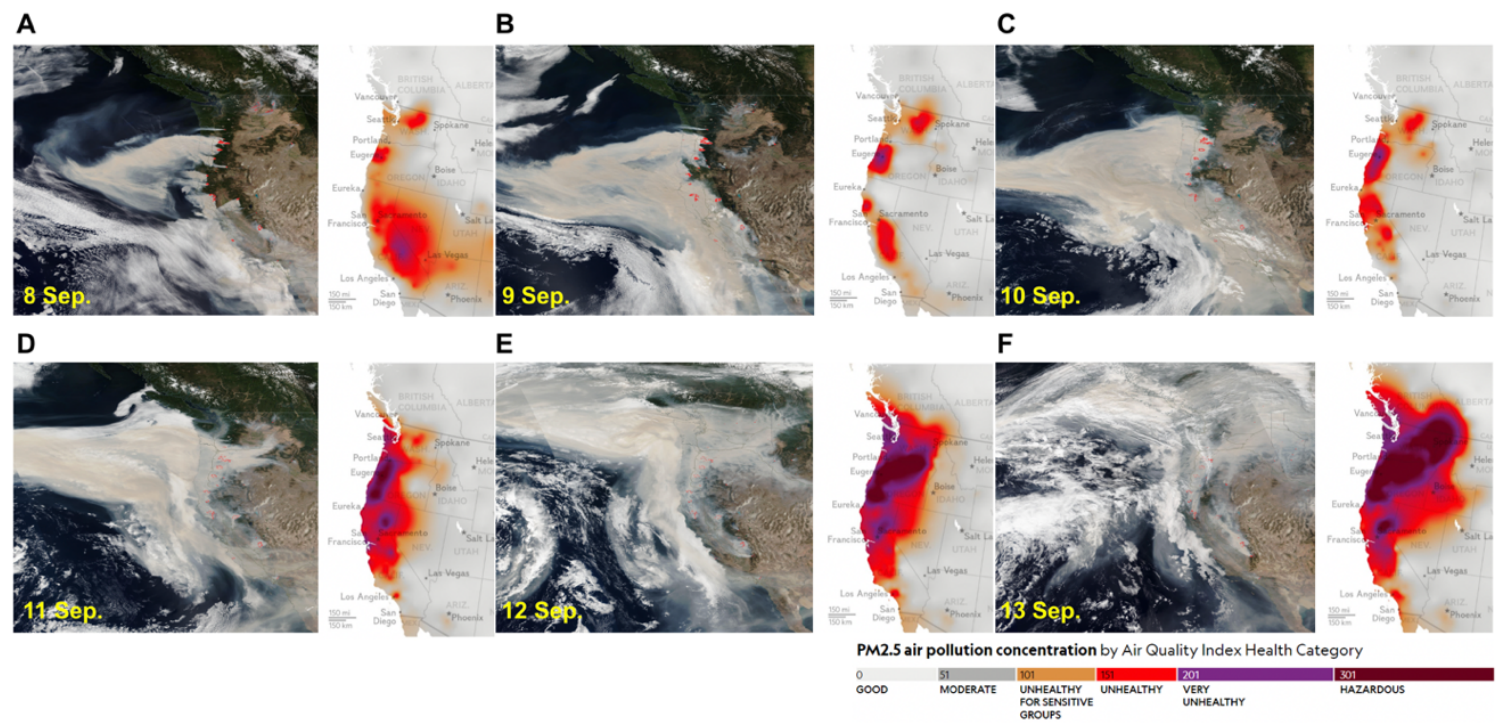

Fig. S1. Satellite image and air quality map during the 2020 western US gigafire event. (A-F) MODIS true color image observed by Terra satellite (left panel) and the USEPA's Air Quality Index map (right panel) during 8-13 September 2020 over the western US. These images are openly accessible at https://worldview.earthdata.nasa.gov and http://berkeleyearth.org. 

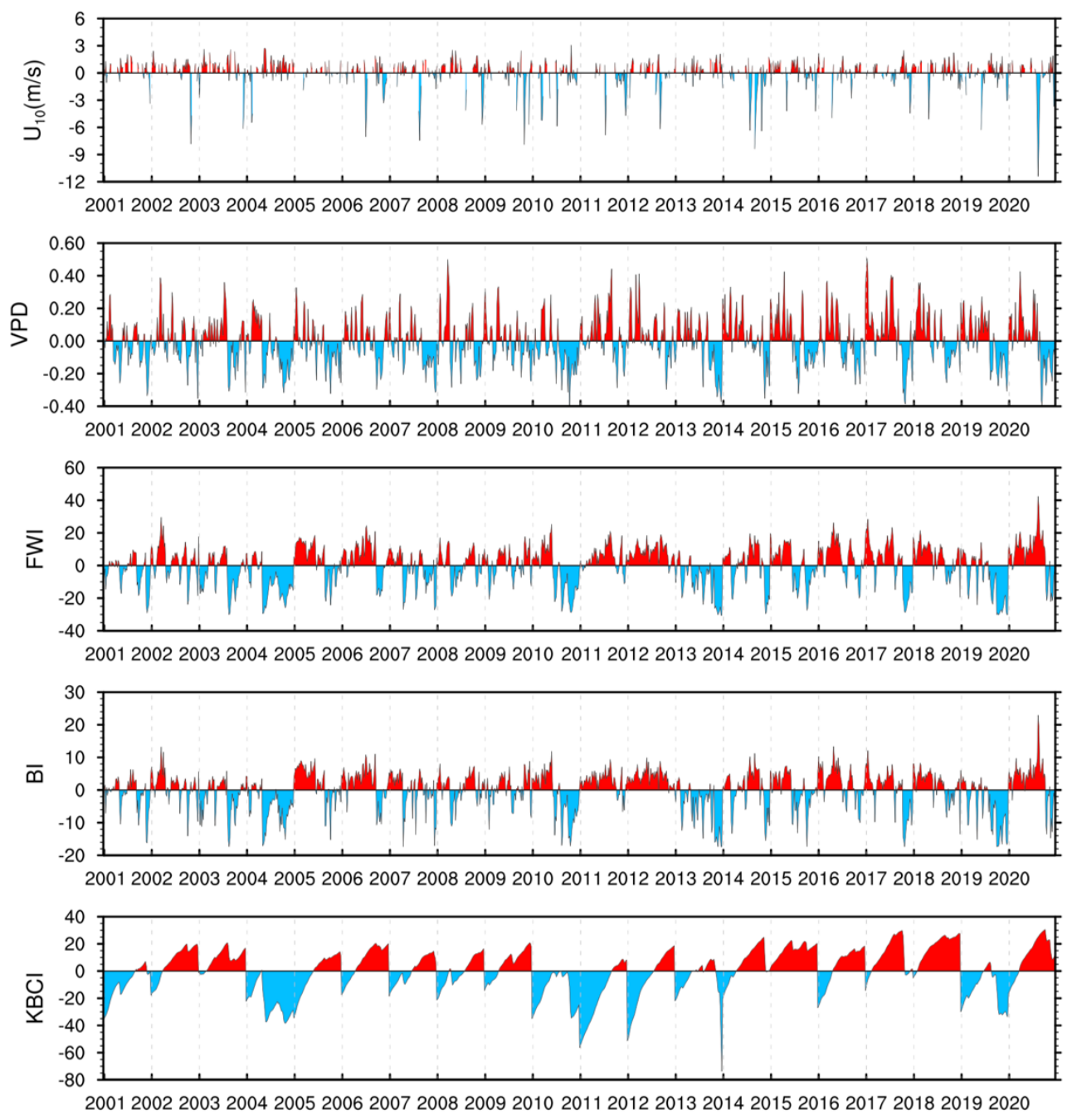

Fig. S2. Anomalies of wind and fire danger indexes in the past two decades. Time series of 10meter zonal wind (U10) and fire danger indexes (VPD, vapor pressure deficit, FWI: Fire weather index, BI: Burning index, KBDI: Keetch-Byram drought index) anomaly in the Oregon Cascade Mountains in August-September from 2001 to 2020. 


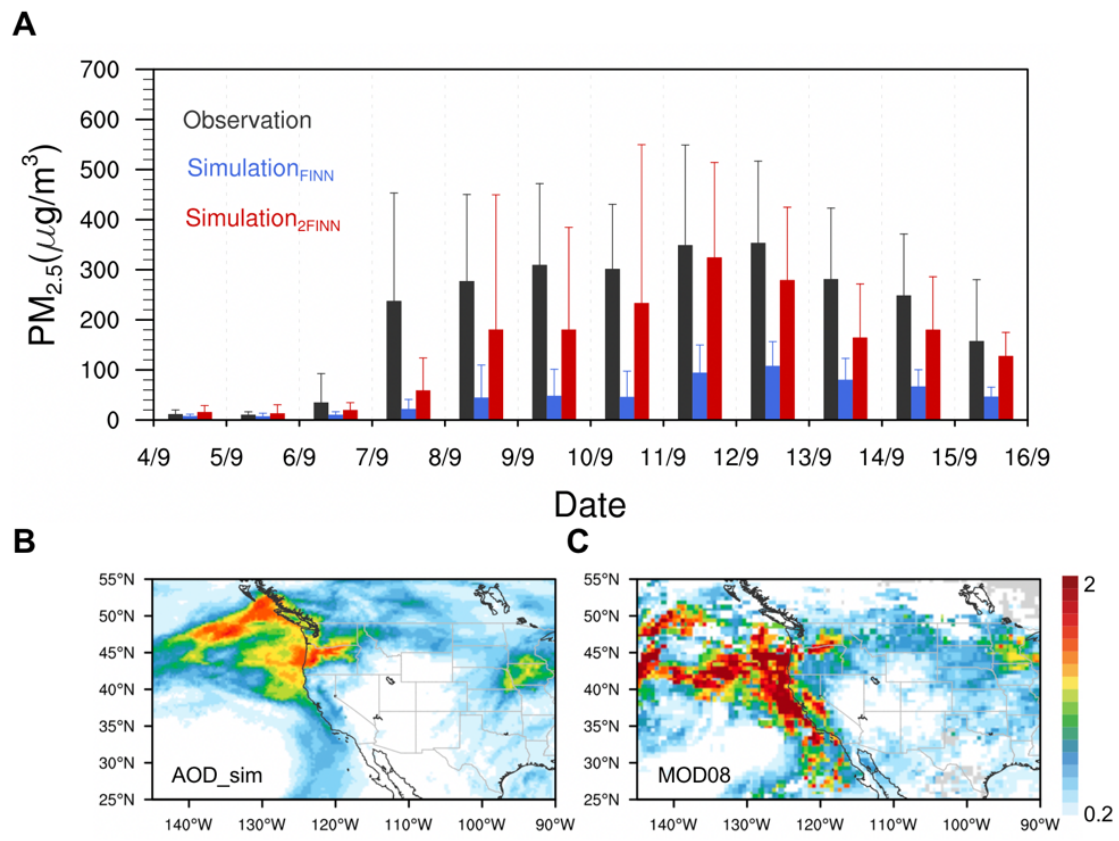

Fig. S3. Evaluation of WRF-Chem simulation by in-situ $\mathrm{PM}_{2.5}$ observations and satellite-derived AOD. (A) Comparison of simulated and observed daily $\mathrm{PM}_{2.5}$ concentrations in Oregon. (B-C) Spatial patterns of MODIS-retrieved (MOD04_L2) and simulated aerosol optical depth during the first half of September. 
A

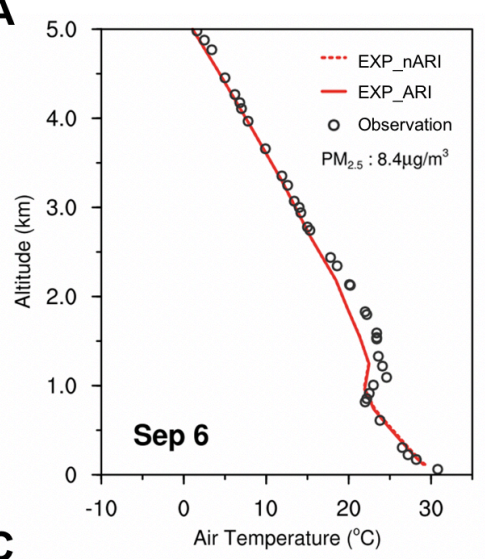

B

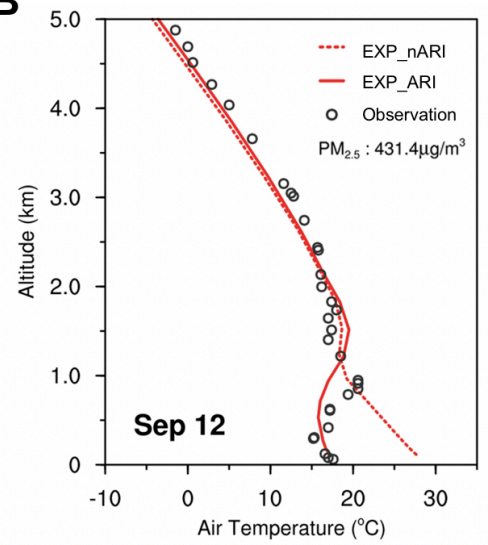

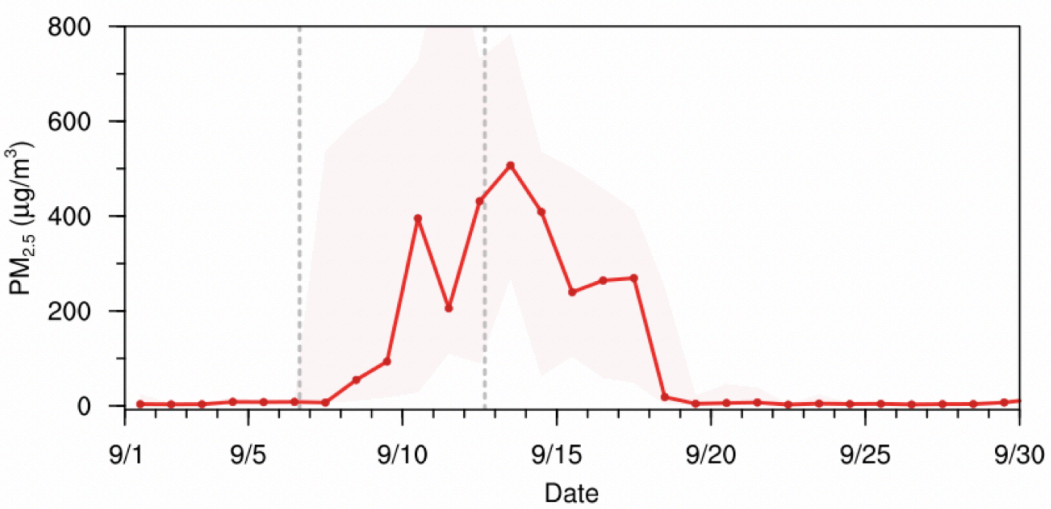

Fig. S4. Evaluation of WRF-Chem simulation by radiosonde measurement of temperature. (A-B) Vertical profiles of observed and model simulated air temperature at the Salem radiosonde station on 6 and 12 September. Dashed and solid red lines present simulations with and without considering ARI, respectively. $\mathrm{PM}_{2.5}$ concentrations are labeled in the top right corner. (C) Time series of daily average (line) and standard deviation (shading) of $\mathrm{PM}_{2.5}$ concentrations at Salem in September 2020. 
A
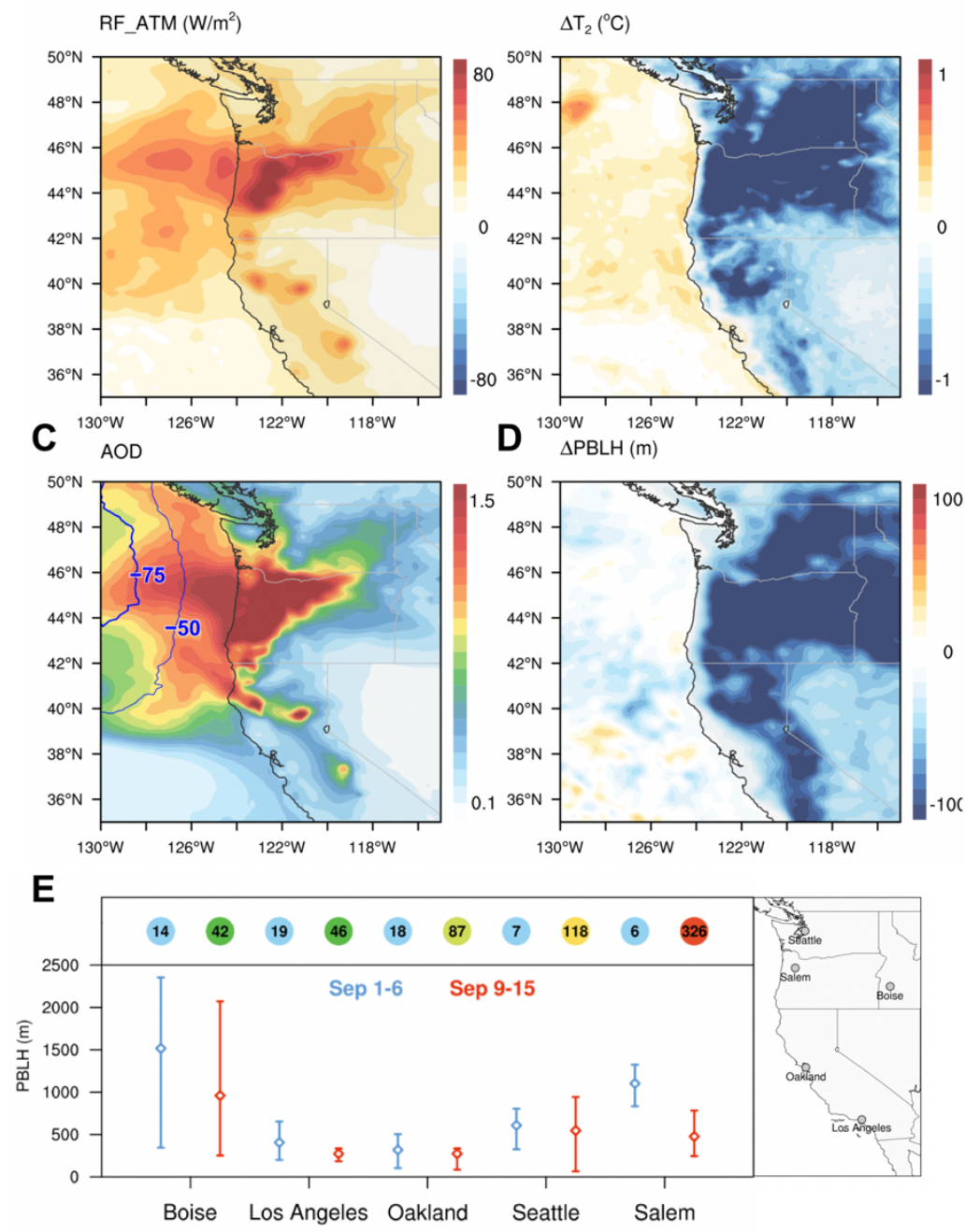

Fig. S5. ARI-induced changes in radiation energy balance, air temperature and $\mathrm{PBL}$ in the western US. (A) Spatial distribution of atmospheric warming (radiative forcing in the atmosphere, RF_ATM) during 10-13 September 2020. (B) ARI-induced 2-m air temperature perturbations. (C) Aerosol optical depth and 1-km pressure ( $\mathrm{hPa}$ ) changes due to ARI. (D) Planet boundary layer height (PBLH) changes due to ARI. (E) Comparisons of PBLH during clean (blue) and polluted (red) time periods at five radiosonde stations in the western US. The dots and bars show the average and ranges of PBLH at 16:00 during the two different periods. Numbers in circles label the averaged $\mathrm{PM}_{2.5}$ concentrations. The geographic locations of radiosonde stations are marked in the right panel. 


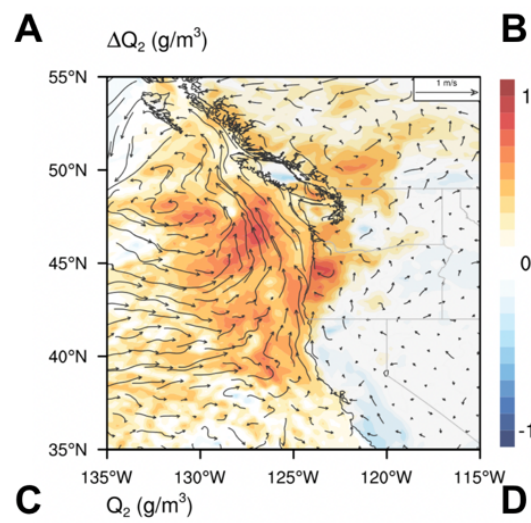

B $\quad \Delta Q_{2}\left(g / m^{3}\right)$
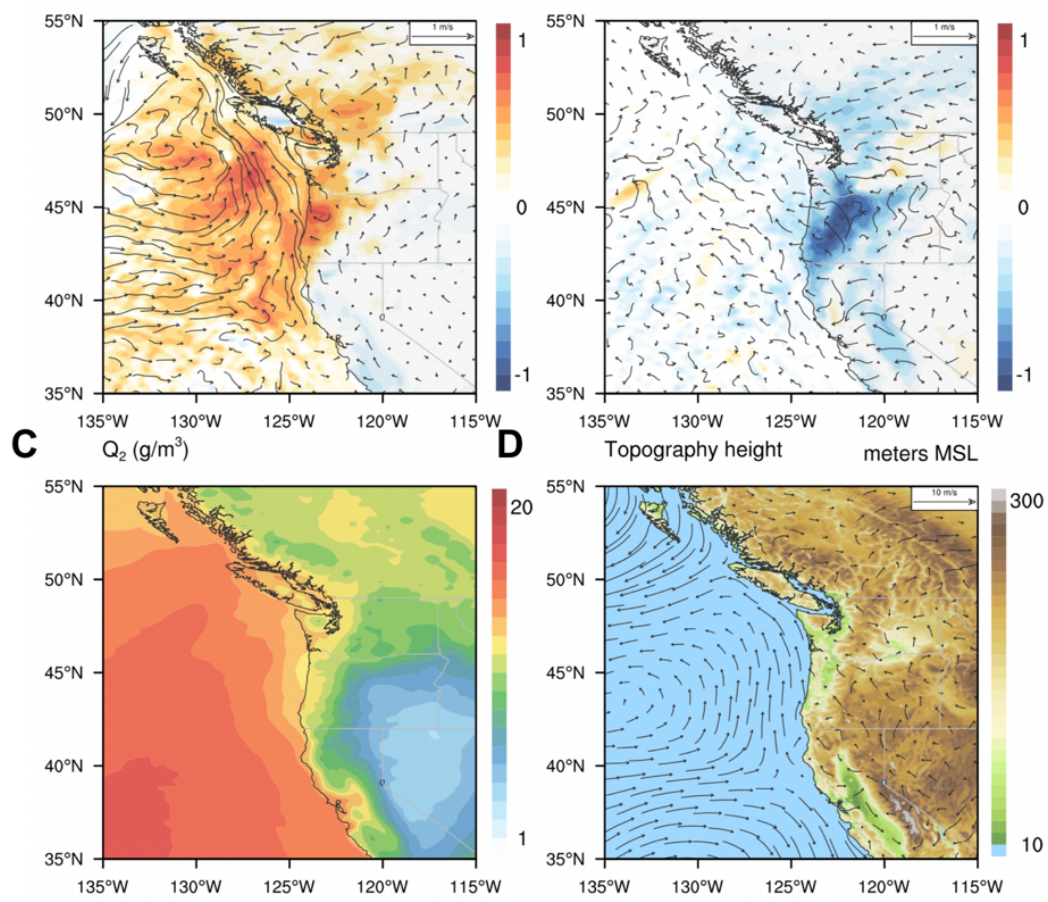

Fig. S6. Changes of water vapor and wind due to $A R I$ over sea and land. (A-B) $Q_{2}$ and $W S_{10}$ responses to ARI over sea and land, respectively. (C) Spatial distribution of $Q_{2}$ in September 2020. (D) Topographic map and averaged circulation in September 2020. 


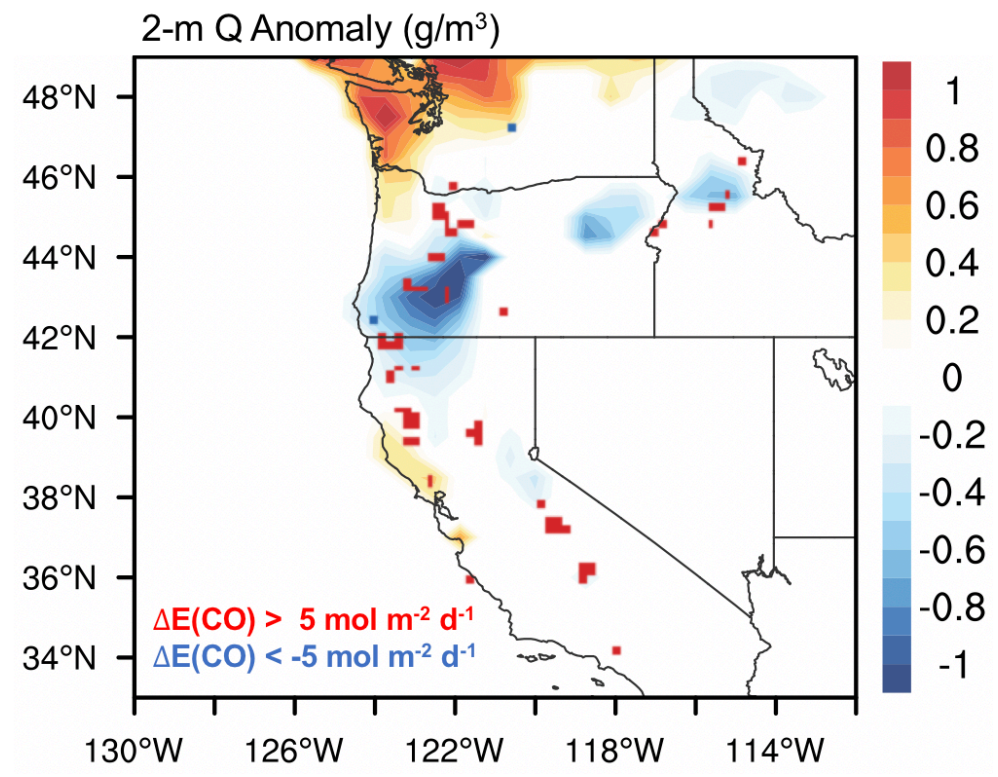

Fig. S7. Q2 anomaly over forest in September 2020 compared with climatological average of 2010-2020. Red and blue squares mark the locations with abnormally high and low biomass emission (CO emission is $5 \mathrm{~mol} \mathrm{~m}^{-2} \mathrm{~d}^{-1}$ higher/lower than the climatological average) in September 2020. 
A

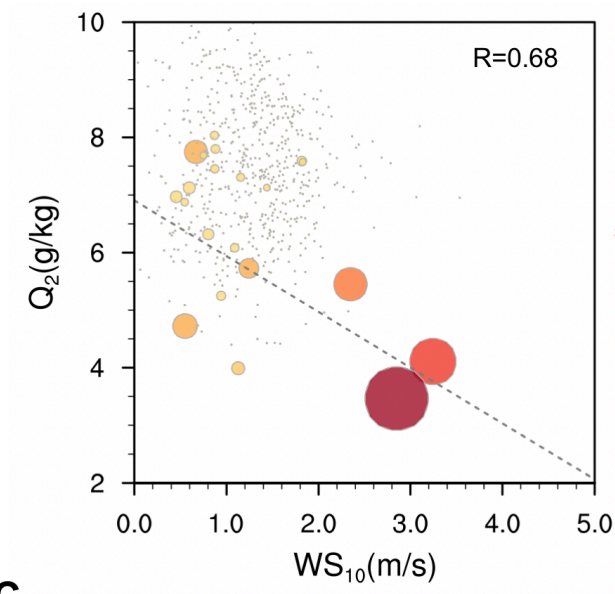

C

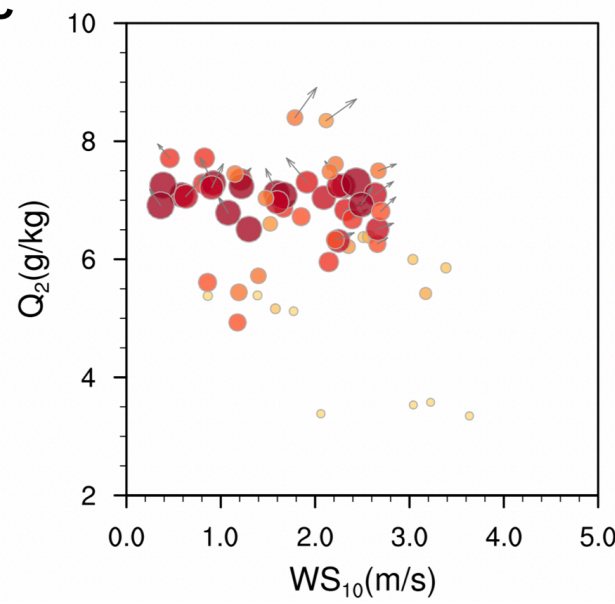

B

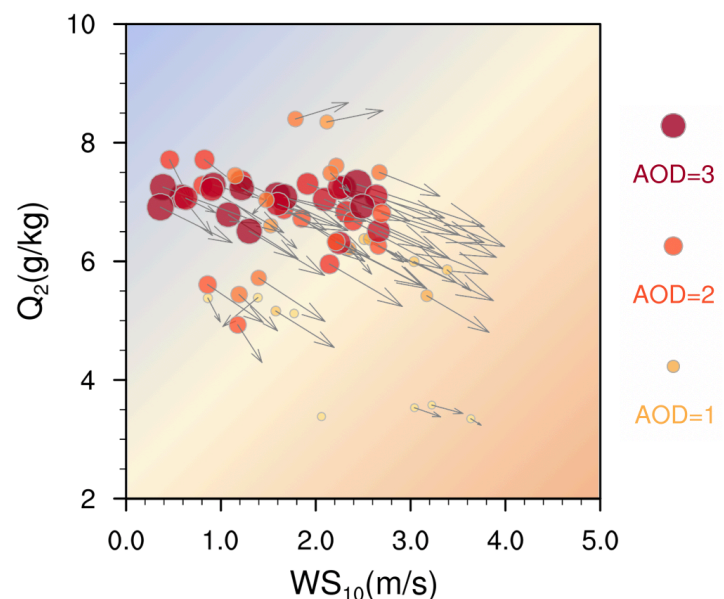

D

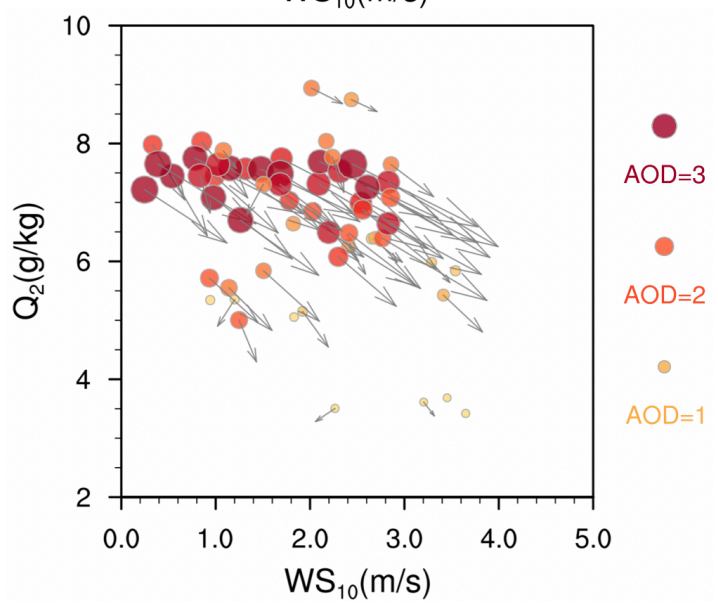

Fig. S8. Relationship between the changes of water vapor and wind due to ARI over sea and land. (A) Relationship between 2-m water vapor Q2, 10-m wind speed WS10 and fire area in Oregon. (B) WS10 and Q2 changes over fire spots due to ARI under different AOD levels during 10-13 September. (C) WS10 and Q2 changes over fire spots due to ARI over ocean during 10-13 September. (D) Same with C, but due to ARI over land. 
A
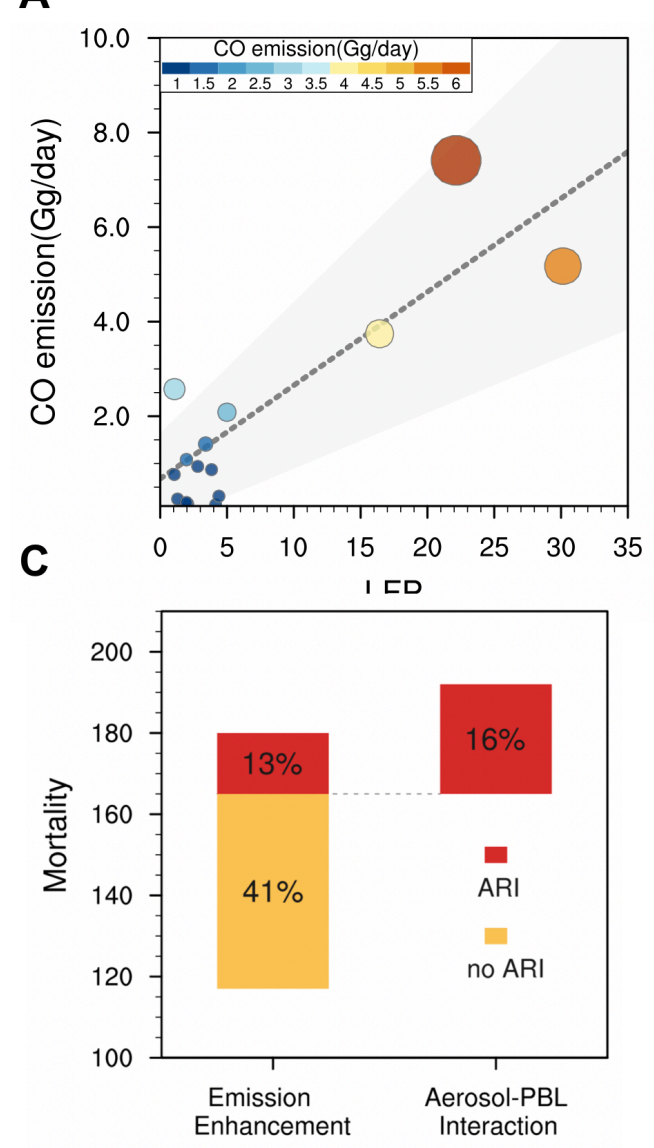

B
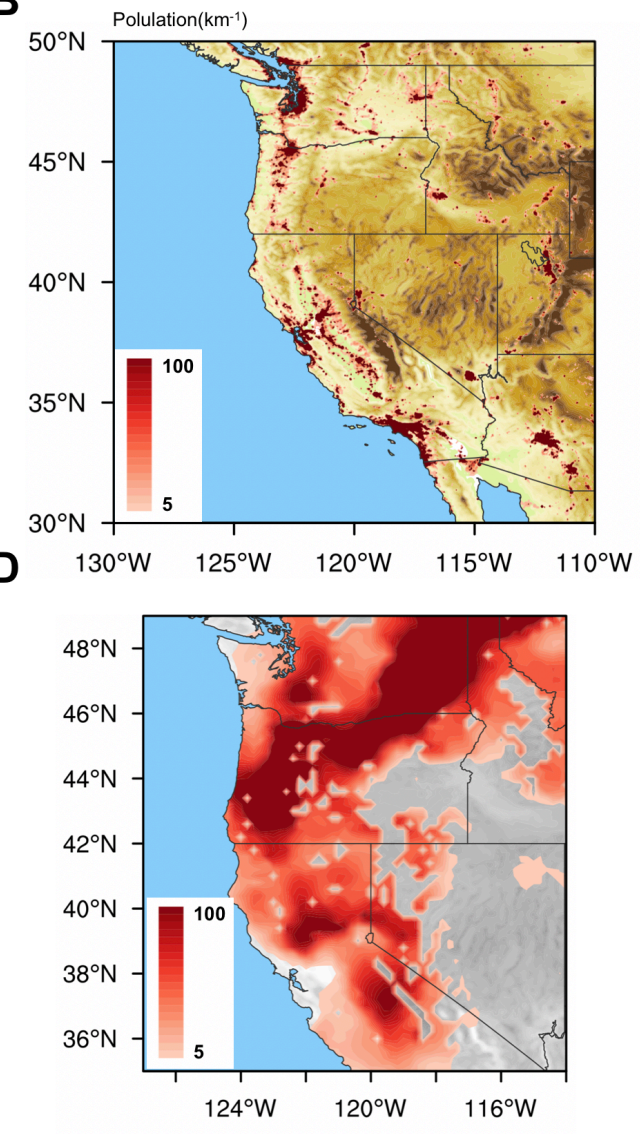

Fig. S9. Wildfire Emission, large fire potential, population density and ARI-induced excess mortality. (A) Relationship between 2-day moving average of LFP and daily fire CO emission in the western US in September 2020. (B) Map showing spatial distribution of topography and population density in the western US. (C) Attribution of excess mortality to emission enhancement and aerosol-PBL interaction in the western US. (D) Relative change of mortality due to fire-weather interaction during 10-13 September in the western US. 